\title{
THE INTEGRATION OF TQM AND BPR
}

\author{
DOI: 10.12776/QIP.V17I2.186
}

\author{
IVANA MARTONOVÁ
}

\section{INTRODUCTION}

Due to the increasing competition and the pressure of globalization, organizations are looking for the best opportunities to improve their processes. Undoubtedly, to succeed on the market it is necessary to continuously reduce the costs, to improve the quality of products and to increase customer satisfaction. Therefore, it is vital to find the ways how to reach the goals as efficiently as possible. It is obvious that TQM and BPR have significantly changed the approach to management systems. On the one hand, TQM is based on continuous improvement; on the other hand, BPR is based on large step changes through redesign, reengineering and a fundamental rethinking of business processes. Even though these two approaches are in some aspects very different, paradoxically, they contain a few similarities which make their integration possible. Based on these similarities, some researchers believe that TQM and BPR are compatible approaches.

\section{METHODOLOGY}

This paper is an empirical survey based work, drawing from extensive literature review, including the analysis and the synthesis of domestic and foreign professional literary sources. The methods for the preparation of scientific research are applied; the methods of gaining new data, methods of data processing are used.

Before developing the methodology it was necessary to theoretically examine the topic. The literature review included studying various researches and studies by authors such as Love and Gunasekaran (1997:192), MacDonald and Dale (1999:38), Allender (1994:42), De Bruyn and Gelders (1997:192), Harrington (1995:125), Kelada (1994:80), Grover and Malhotra (1997:199), Gonzalez and Martinez (1999:19), Paulova (2009:79). Each of these authors shares the opinion that it is possible to integrate and jointly use both approaches of process improvement within an organization. This evidence is consistent with the argument that it is possible to integrate TQM and BPR. The provided study of the 
methodology takes into account the procedures available in scientific worksand and finally provides a framework to effectively combine the TQM elements and the BPR elements.

Subsequently, an analysis of the current status, relating to the use of the principles of TQM and BPR in improving processes was carried out in four selected organizations. The analysis was performed through interviews using a predefined questionnaire. The aim of this analysis was to obtain the information needed for the subsequent development of the methodology of integrated approaches of TQM and BPR. The respondents were asked 25 questions in total, which concerned the level of the implementation of TQM and BPR in the organizations, the ways and methods the organizations currently use to improve their processes, which targets have the greatest importance for the organization, which elements are used by organizations to improve their processes (TQM or $\mathrm{BPR}$ ) and which strengths of the process improving methodologies are important for the organizations.

\section{LITERATURE REVIEW}

To reach the goal of improving quality, organizations use different improvement tools and philosophies. There is no doubt that TQM (Total Quality Management) and BPR (Business Process Reengineering) are efficient strategic approaches to achieve this goal. According to Ishikawa, TQM is based on the principle of continuous improvement of products and processes aimed at continually satisfying customer expectations regarding quality, cost, delivery and service. (Ishikawa, 1990:24)

TQM has no formalized procedure. The exact content of TQM implementation is not clearly determined. TQM reflects the experience of Japanese and American companies focused on quality management. Promoting the TQM philosophy caused the development of models such as EFQM and MBNQA.

According to Imeri and Kekäle (2013) there are two different approaches of TQM:

- Soft TQM - „softe TQM elements incorporate the following: total employee involvement, continues improvement, strategic quality planning, continues training, teamwork, empowerment, customer satisfaction, information and analysis, supplier management, topmanagement commitment and support, democratic management style, culture change.

- Hard TQM - the most common „hard"e elements of TQM are statistical process control, ISO 9000 series, HACCP, kaizen approach, JIT, six sigma, EFQM, 5S s, scatter diagrams, benchmarking, quality function deployment, run charts and control charts, pareto analysis, matrix 
diagram, histograms and process charts, tree decision diagrams, critical path analysis and fishbone or Ishikawa diagram.

The quality motivation is the major task for modern business management. Without quality motivation it is impossible to implement any organisation culture and TQM. (Hekelová, 2000:3) There is many ways for increasing the motivation of the emloyees. For example: job rotation, bonus systems, job enlargement, job enrichment, quality campaigns, quality circles, activities etc.

On the other hand, there is reengineering which is defined by Hammer and Champy (2004:32) as the fundamental rethinking and radical redesign of business processes to achieve dramatic improvements in critical contemporary measures of performance such as cost, quality, service and speed. The BPR goal is to reach a breakthrough gain and achieve dramatic process performance (Dai, 2007:36)

It is well known that TQM focuses on customers together with emphasis on employees, suppliers, shareholders and other stakeholders aims to safeguard mutual wealth consequently strengthening the priority of all stakeholders. That means there must be found optimum in quality, when it does not threaten to violate the needs of other stakeholders. (Susniene and Vanagas, 2005:71) TQM can create a culture and it is that aspect of TQM that managers must focus on. (Gore, 1999:164) The managers should also focus on the needs of customers and consumers and their satisfaction. BPR also aims at satisfying customer expectations regarding quality, cost, delivery and service, however, its approach to improvements is more radical. (Carpinetti, et al., 2003:544) BPR is based on the radical horizontal restructure of company in order to improve performance of the processes, to obtain improvements in short term. Reengineering and continuous improvement may result in a higher innovation - rate, because these are parts of an overarching process, and that overarching process is Quality Management. The terms for these two components of the Quality Management process are "process innovation" and "process improvement". (Pürstinger, 2005:75)

TQM or continuous improvement means programs and initiatives which emphasize incremental improvement in work processes and outputs over an open-ended period of time. (Omnex, 2013) The TQM results should not be seen in the short term. The time that customers come to recognise the improved quality of the product and services can also be long. In contrast, reengineering, also known as business process redesign or process innovation, refers to prudent initiatives intended to achieve radically redesigned and improved work processes in a specific time frame. Leadership is really important for effective BPR deployment, and successful leaders use leadership styles to suit the particular situation and perform their tasks, giving due importance to both people and work. The management should also take care to provide adequate funding, set new standards as well as encourage others to be open to innovative approaches. Many reengineering projects fail to be completed or do not achieve bottom-line 
business results. (Omnex, 2013) The reengineering project can be succeed only if top managers invest their time and energy. Without strong leadership from top management can BPR project fail. The employees may feel that their jobs are under attack. But managers can overcome opposition to the new design if they approach reengineering as a painful but necessary steps.

However, in terms of time orientation, the type of change for each of the approaches is quite different. TQM is seen as a continuous programme that continually strives towards an ideal such as zero defects or 100 percent customer satisfaction. In contrast, BPR is seen as a one-off event aimed at creating new systems and processes. (Harvey and Millet, 1999:36) Each of the approaches being examined shares the basic aim of increasing organisational efficiency. $T Q M$ are also concerned with the needs of people within the organisation and achieve organisational efficiency through the better use of people. By contrast, $B P R$ often operates from a management vision, which may or may not be employee-friendly. (Harvey and Millet, 1999:37) One of the most common problems is the resistance of employees to make the necessary changes. This resistance should be anticipated and ways to overcome it given adequate attention. TQM relates to the quality of products or services and is useful where quality is seen as a way to increase competitive advantage. BPR is not narrowly focused on quality and defines improvement more broadly. (Harvey and Millet, 1999:37) TQM culture would also facilitate the development of human resources but, in this instance, the development would focus on customer service skills, technical skills and other skills that would improve service quality. (Harvey and Millet, 1999:38) In contrast to these approaches, BPR is more objective in nature. BPR is about redesigning systems and so requires a culture that will be willing to accept one-off, frame-breaking changes. Each of the approaches supports a shift away from individual, highly formalised work practices in favour of team based work. TQM and BPR demand more innovation and input from the workforce in terms of new ideas for work processes and methods. (Harvey and Millet, 1999:39)

Although it seems that approaches differ in many factors, they are based on very similar assumptions. The most basic similarity is that each of them is based on the planned change. TQM is focused on incremental changes and BPR is focused on radical changes. Reengineering is radical and usually reaches greater changes. However, TQM is going in the same direction, but it is slower and deals with minor problems. It is focused on improving the existing processes. Once TQM is implemented into the organizational culture, it works somewhat independently and does not require great management involvement. In contrast, reengineering requires intensive effort of the top management.

The similarities and differences between TQM and reengineering were also described by Gore (1999:167). They both include a focus on process flows across functional boundaries. They both include a focus on the customer and work to define the current process and identify problems. There is a major apparent difference in the quality focus on continuous improvement versus the 
reengineering goal of the best that can be conceived. The elements of TQM that are missing from reengineering are continuous improvement, a focus on people, participation of "insiders", and teamwork and it is these elements that make up the central difference between the two approaches. (Gore, 1999:167)

The authors MacDonald and Dale (1999:38) argue that, based on many common features, it is possible to use BPR and TQM jointly at one organization. Also Love and Gunasekaran (1997:192) are of the opinion that TQM is a good starter for BPR.

Other authors who have analyzed the possibility of integrating BPR and TQM are Gonzalez, Martinez and Dale (1999:19). They realized that further research is needed and their analysis provides only a broad set of guidelines. Nevertheless, according to them, the application or adaptation of BPR methodologies for the implementation of TQM principles seem to be possible.

It is possible to integrate TQM and BPR, but it is necessary to ensure their mutual "separation". It is also necessary to differentiate what reengineering teams are and to separetely set TQM teams. Each of these two strategic approaches has its advantages and disadvantages and they are fairly well supplementary under certain conditions. It must always be clear what we want to achieve with change. If gradual improvement is sufficient, it is appropriate to use TQM - moderate changes. If greater annual changes in business results are needed, radical reengineering changes must be implemented. Change is selected according to business needs. However, it is possible to start with TQM, continue with reengineering, then certain time with TQM, etc. (see Fig. 1). TQM can be used on implementation of moderate changes after radical change through reengineering. TQM as a system that drives improvement is very analogous to a Kaizen approach. The elements and characteristics are considerably supportive of each other, and the two philosophies mandate a similar organizational mindset. Consequently on the road of a company to TQM, a Kaizen approach and any of its tools under its umbrella in practice, is a compatible valuable tool to TQM. (Lolidis, 2006:30) The TQM tools are tools for the systematic improvement in the small steps. (Zgodavová, 1998:68)

Allender (1994:42) concluded that nothing in the TQM philosophy dictates that continuous improvements must proceed in small steps and that improvements are welcomed in either small steps or gigantic leaps. Thus, the breakthroughs envisioned by BPR are indeed consistent with TQM.

De Bruyn and Gelders (1997:192) think that TQM is an enabler of reengineering. According to Harrington (1995:125) and Kelada (1994:80) are these two approaches complementary and that reengineering has to have TQM aims at the forefront in order for it to be successful. Also Grover \& Malhorta (1997:199) state that TQM can often serve as the building block for subsequent reengineering efforts. 
Gonzalez, Martinez and Dale (1999:19) recognized the need to perform more researches, but application, or adaptation of BPR methodologies for implementing TQM principles seem to be possible.

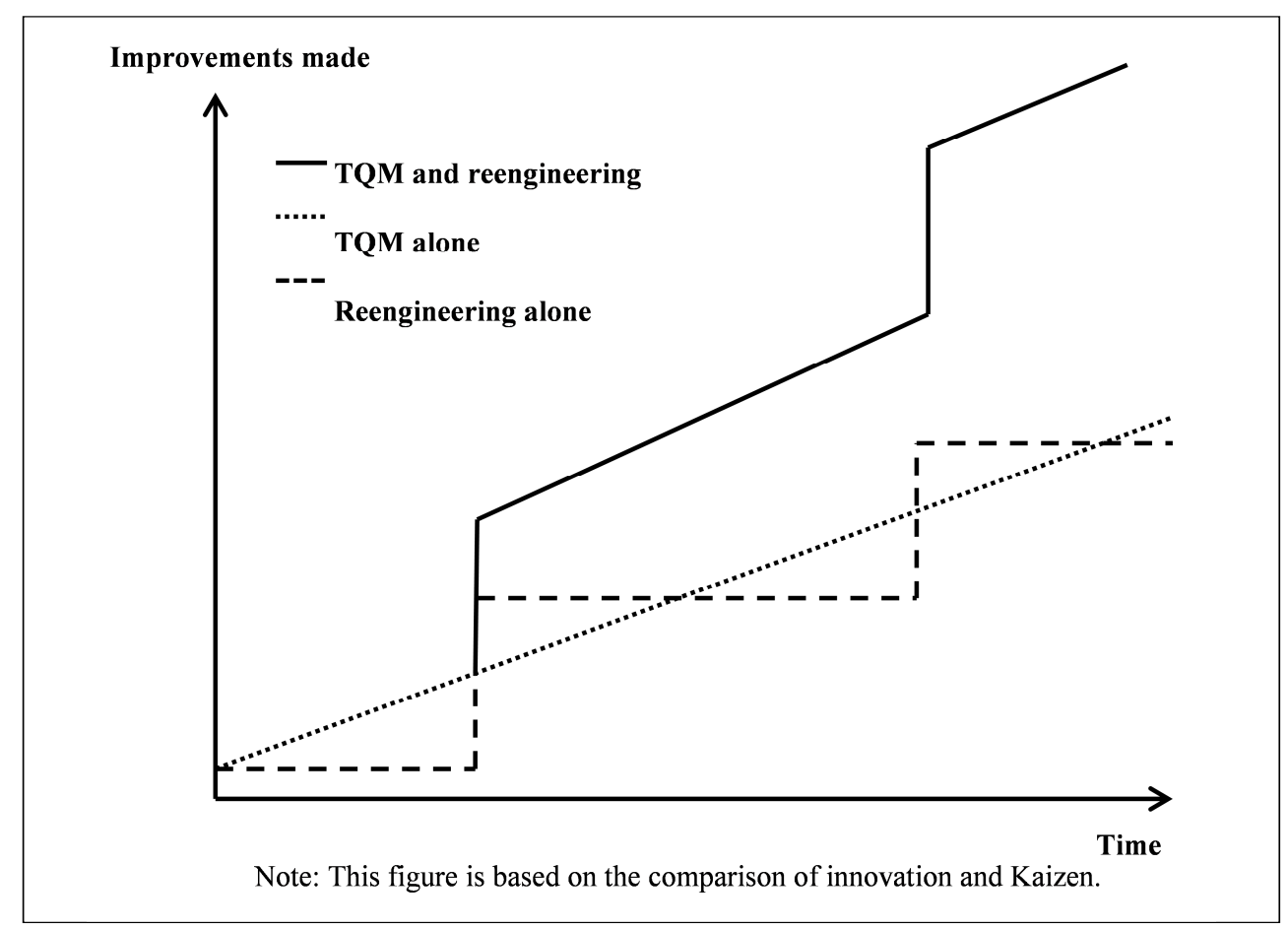

Figure 1 - Advantages of applying TQM and reengineering jointly (Lorente, 1999:19)

Many authors argue that by the simultaneous usage of TQM and BPR within one organization better results can be reached than when the TQM and BPR are used alone. (Martonová, et al., 2013:160) In case that in organization simultaneously run both improving programs at the same time, must be clearly defined status between them and all employees must to know it.

Today, on the verge of the second decade of the twenty-first century, our foremost issue is the debt crisis of several EU and other countries, and in this situation we believe that it is most appropriate to focus our efforts on success, whilst we take it that success is a sustainable prosperity of individuals and organisations. (Zgodavová and Slimák, 2011:1)

The competitive pressures have forced most companies to increase their focus on using the world's best improvement techniques. A major benefit of globalization is an access to improvement techniques being developed around the world. Globalization brings the use of new tools and methods and methodologies in different factories all over the world. (Šurinová and Paulová, 2009:101). TQM and BPR belong to these best improvement strategic approaches . 


\section{SURVEY RESULTS DISCUSSION}

To find out about the current situation and to define the strengths and weaknesses in the TQM and BPR use in Slovak organizations, an interview was carried out. Each of the interviewed organization had some experience at least with one methodology and was intensely dedicated to process improvement by using the various tools and techniques of quality management. It was the impact of different factors on improvement process efficiency that was heavily investigated.

The findings show that organizations ascribe high importance to increasing sales, increasing product quality, reducing costs, increasing the process efficiency and deliveries on time. Likewise, each of them use BPR elements, as well as elements of TQM in their improvement activities (see Fig. 2). In most cases, organizations use "soft" elements of TQM, but if needed, they use the "hard" elements of reengineering, too. It can be assumed that organizations should be able to use a "mix" of elements of both approaches simultaneously.

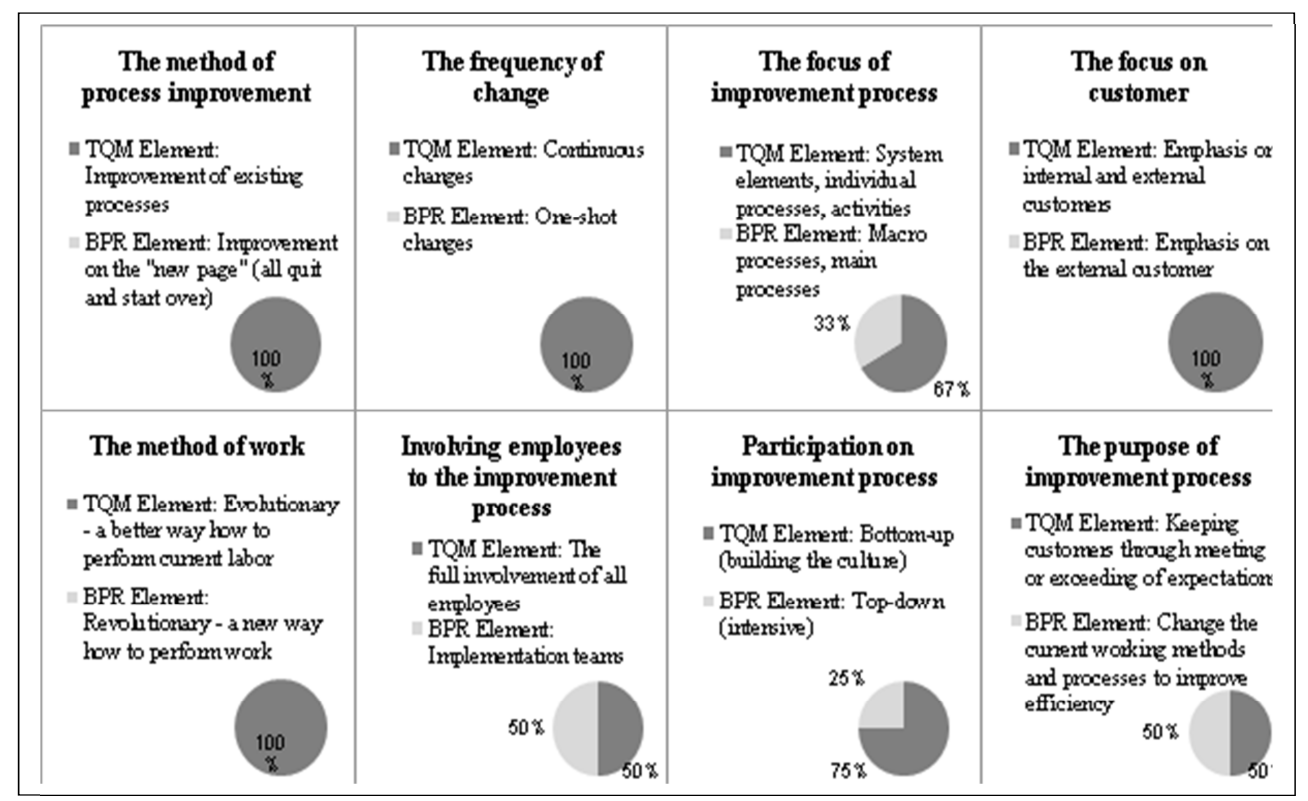

Figure 2 - The use of elements of TQM and BPR during process improvement

The survey made it obvious that respondents find customer satisfaction and subsequently the focus on continuous process improvement extremely important (see Fig. 3). That is why the proposed methodology should take these facts into consideration.

Finally, the respondents were asked whether they would implement the methodology of integrated TQM and BPR approaches in the organization if the methodology was provided and its effectiveness was verified in practice. The respondents expressed interest in the compiled methodology in all organizations. 
Based on the above-mentioned studies and results of the interview, the methodology of TQM and BPR approaches integration was developed. The methodology is described below.

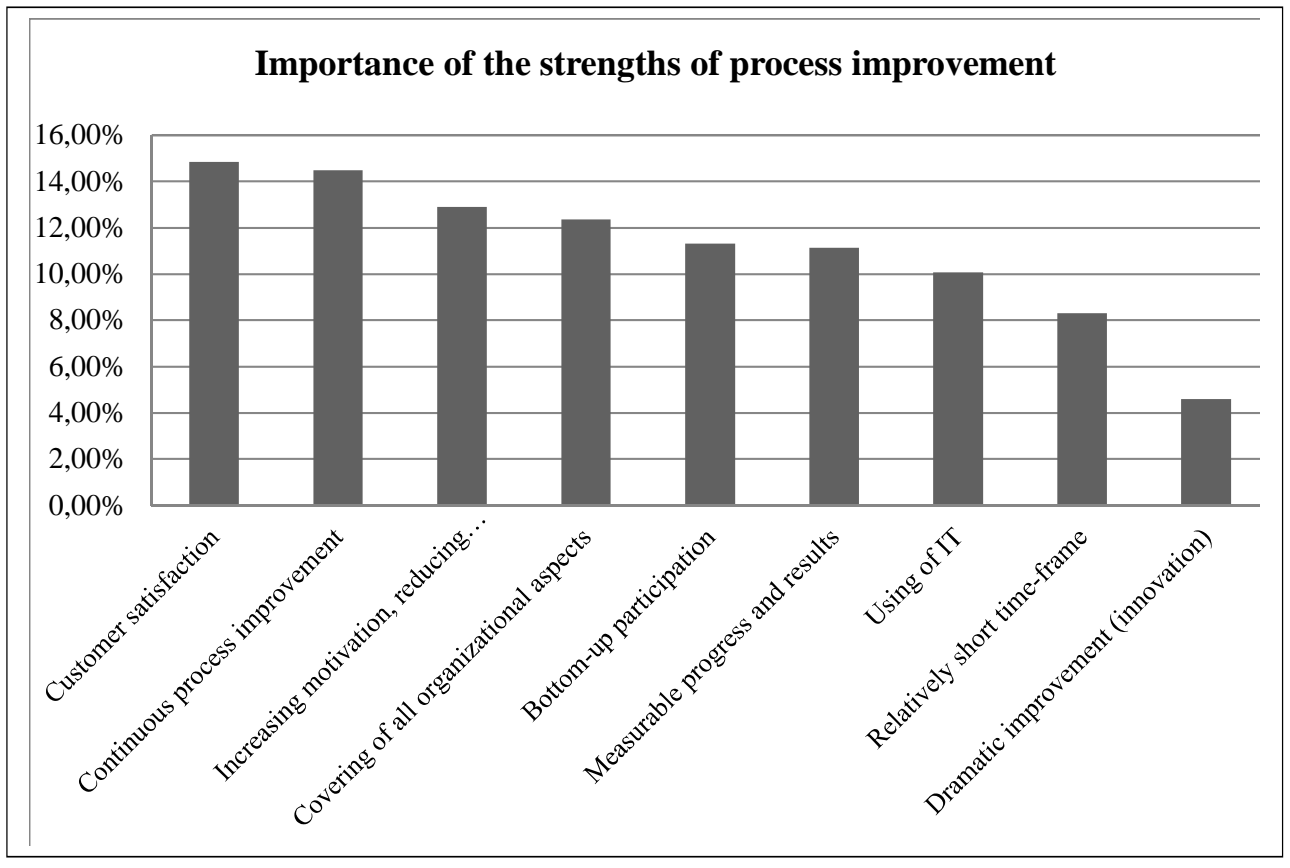

Figure 3 - The importance of the strengths of process improvement

\section{METHODOLOGY OF THE INTEGRATED TQM AND BPR APPROACHES}

Building on prior literature and survey results, we further attempt to define the methodology of the TQM and BPR integration. Based on literature research and case studies described above, and also on the information obtained from the interview in four selected organizations, the methodology of integrated TQM and BPR approaches has been developed. Subsequently, the applicability of the developed methodology was verified in one selected organization. The methodology consists of five phases, described on Fig. 4, and are described below. Single phases of methodology are based on the PDCA Cycle.

\section{Phase 1 - Preparation}

First, it is necessary to identify the persons who will participate in the project, i.e. creating a "design team". This team will be established by the project sponsor. The team will be tasked to create an improvement project and subsequently initiate and monitor the activities related with the successful implementation of the project. Another task of the project sponsor is to motivate the team members so that the costs associated with motivation (financial rewards, vacations, etc.) 
could be lowered, and on the other the hand, the team members would be incited to perform the assigned tasks as effectively as possible. Probably the most commonly used incentives to motivate the team to work together are the promise of rewards for the project, deadlines etc. The best practice to motivate the team includes regular meetings and discussions within the team.

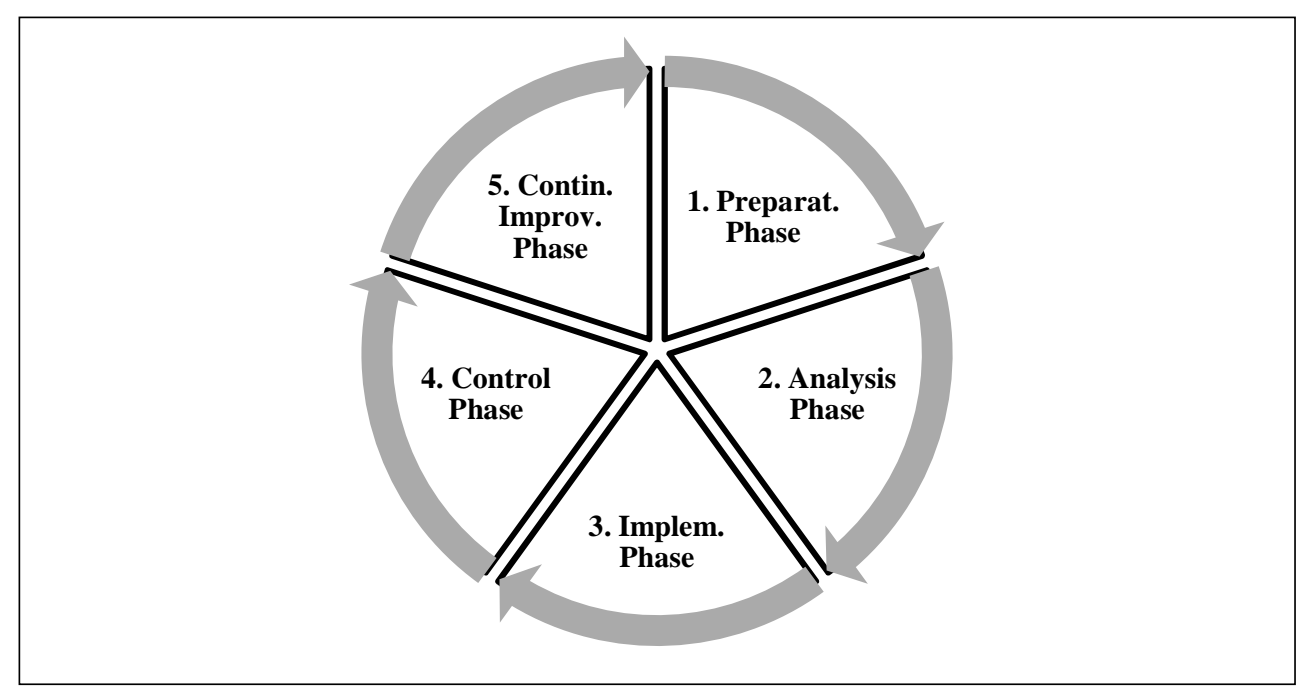

Figure 4 - The methodology of integrated TQM and BPR approaches

\section{Phase 2 - Analysis}

\section{- Step 1: Analysis of requirements on processes}

At the beginning of this phase, it is essential to answer the question: "Why have we decided to change?" If the reason for change is the general purpose and the internal needs of the organization, the first step of this phase will be determining organization goals (point 1 a)). Otherwise, if the reason for change is an external pressure from customers, the first step of this phase will be customer requirements analysis (point $1 \mathrm{~b}$ )).

Point 1 a): Determining the organization goals

These goals should be summarized by the design team in cooperation with the top-management representatives. Most organizations set goals regularly (usually on an annual basis), so the team only needs to reach the goals for current time period.

Point 1 b): Customer requirements analysis

The analysis of customer requirements can be done through questionnaire surveys, interviews or brainstorming with the representatives of the key customers. This step is very important because often organizations do not know what is important for the customer. If the customer's requirements are identified at the beginning of the process, their satisfaction will increase at the end of the process improvement. 
Point 2: The degree of achieving the goals/requirements

In this step it is necessary to verify the degree of the objectives (requirements) fulfillment, i.e. to identify the current state of goals achievement (requirements). The design team determines the degree of fulfillment according to the criteria in Table 1 for goals (requirements) which were determined in point 1.

Table 1 - Degree of achieving goals/ requirements

\begin{tabular}{|l|l|l|}
\hline Level of goal achievement & Criterion & Points \\
\hline Excellent achievement of the goal & $>90 \%$ & 1 \\
\cline { 2 - 3 } & $81-90 \%$ & 2 \\
\hline \multirow{2}{*}{ Good achievement of the goal } & $71-80 \%$ & 3 \\
\cline { 2 - 3 } & $61-70 \%$ & 4 \\
\hline \multirow{2}{*}{ Moderate achievement of the goal } & $51-60 \%$ & 5 \\
\cline { 2 - 3 } & $41-50 \%$ & 6 \\
\hline \multirow{2}{*}{ Weak achievement of the goal } & $31-40 \%$ & 7 \\
\cline { 2 - 3 } & $21-30 \%$ & 8 \\
\hline & $11-20 \%$ & 9 \\
\cline { 2 - 3 } & $<11 \%$ & 10 \\
\hline
\end{tabular}

- Step 2: Analysis of the current status of processes

This step requires to prepare a process map (if the organization does not have it), and to determine which processes are Value Added and which are Non-Value Added. The identification of the Value Added Processes is essential from the customer's perspective. It is necessary to evaluate the processes and classify them into categories of customer Value Added Processes - called Real Value Added Processes, organization Value Added - called Business Value Added Processes and No Value Added Processes. When the processes/activities are assigned into the three groups, it is critical to look for opportunities to improve them. First, it is relevant to eliminate the causes of No Value Added Activities. Business Value Added Activities should be analyzed - whether it is necessary to perform them, and whether there are better ways to perform them. Value Added Processes should be selected and subjected to improvement by further steps and phases.

- Step 3: Selection of processes for change, selection of representative performance measures and their current status

Point 1: Selection of processes for change

The first step is the selection of the processes to improve. A process, to be considered for improving, has to be strategic and Value Added (Salegna and Farzaneh, 1996:14) - see step 2. The process selection should be realized by using Table 2. Into the first column either the goals of the organization or the customer requirements will be entered (see step 1). The "Degree of Importance" column should be filled with the corresponding value, according to the following scale: 
1 - 2 Not important

3 - 4 Partially important

5 - 6 Important

7 - 8 More than important

9 -10 Very important

To determine the level of importance according to the customer's requirements, it is necessary to ask the customer directly. In case of determining the importance degree according the organization's goals, it is necessary to ask the "key persons" who are able to provide that information. Into the third column it is necessary to fill in the degree of goal achievement or customer requirements (score 1-10), which we identified in step 1 . Into the 4 to $\mathrm{N}$ columns we enter all the Value Added Processes identified in step 2.

Table 2 - Selection of processes for change

\begin{tabular}{|c|c|c|c|c|c|c|c|c|}
\hline \multirow{2}{*}{$\begin{array}{l}\text { The } \\
\text { organization } \\
\text { goals / } \\
\text { customer } \\
\text { requirements }\end{array}$} & \multirow{2}{*}{$\begin{array}{l}\text { Importance } \\
\text { degree }\end{array}$} & \multirow{2}{*}{$\begin{array}{l}\text { Achievement } \\
\text { degree }\end{array}$} & \multicolumn{2}{|c|}{ Process 1} & \multicolumn{2}{|c|}{ Process 2} & \multicolumn{2}{|c|}{ Process N } \\
\hline & & & Link & Score & Link & Score & Link & Score \\
\hline $\begin{array}{l}\text { Goal / } \\
\text { requirement } 1\end{array}$ & & & & & & & & \\
\hline $\begin{array}{l}\text { Goal / } \\
\text { requirement } 2\end{array}$ & & & & & & & & \\
\hline $\begin{array}{l}\text { Goal / } \\
\text { requirement } \mathrm{N}\end{array}$ & & & & & & & & \\
\hline Sum & & & & & & & & \\
\hline
\end{tabular}

In the next step, it is necessary to determine the link between the goals (or customer requirements) and processes according to the following scale:

1 - 2 Very poor

3 - 4 Low

5 - 6 Slightly strong

7 - 8 Strong

9 - 10 Very strong

This value should be filled in the "Link" columns. The "Score" is to be filled with the number calculated by multiplying the values in the "Importance degree", "Achievement degree" and "Link" columns. The final step is calculating the sum of the scores of each column and entering it into the "Sum" line. Reading the table, it is easy to identify the priorities, i.e. selecting the processes which will be improved first, the second, etc. This analysis shows which processes are critical and important to achieve the most important goals. For example, if an organization needs to reduce the costs or the price, it will have to prioritize increasing the productivity. 
Point 2: Selection of representative performance measures and their current status

Secondly, it is necessary to choose representative performance measures, which will indicate the magnitude of the change that will be achieved. The Key Performance Indicators (KPI) quantifies the overall performance of the organization in relation to relevant global objective or critical success factor. The overall performance of the organization is based on the performance of its individual parts, so it is very important to have an accurate distribution of selected indicators for specific processes. Well selected KPI allow monitoring the performance of a particular process in order to produce an accurate output and added value. Consecutively, it is also required to diagnose the current state ot the selected criteria.

\section{Phase 3 - Implementation}

\section{- Step 1: Analysis of selected processes}

This phase analyzes the selected processes to find their defects and their causes. The purpose of the analysis is to identify the problems in the processes, the No Value Added activities, the inefficient time in processes, and also to identify the possibilities of rapid changes. Subsequently, the causes of the problems are found. Obviously, a sound knowledge of analytical methods is required to achieve a quality analysis. They are tools, methodology, including evidence, evaluation and the interpretation of the found information. It is vital to have a precisely defined object of the analysis and to cooperate with experts in the particular field. The analysis should create a realistic image, based on relevant information, and prepare room for taking measures to eradicate the problems.

\section{- Step 2: Creation of solutions}

After identifying the problem(s), the 'design team' is supposed to create ideas which would remedy the situation with the problematic processes. If it is possible (in the case when the situation allows multiple solutions), it is better to make more alternatives of possible solutions, which are to be evaluated and compared and then the team should choose the most suitable one. After the choice of the optimal solution has been made, a plan of implementation is prepared.

\section{- Step 3: Implementation plan preparation}

Point 1: Collecting initial information

The questions in Table 3 should be answered before making an implementation plan. The first question examines the object of improvement. It is based on the outcome of phase 2, where the processes to change and improve have been selected. If the answer to the question is 'macro process or main process', the creators of the implementation plan have to take into consideration that eliminating the resistance of a larger number of employees will be needed than if the change only concerned only a part of the system or a single process. 
'Employee resistance elimination' should be one of the steps in the implementation plan. It is also necessary to define which employees will be subjected to change and to whom the change will be beneficial. If the change is beneficial for both the customers and the employees or internal customers, no extra focus on employee motivation will be needed. The benefit for their working process itself will serve the purpose. On the other hand, if the change only benefits the external customer, motivating the employees will have to be included in the implementation plan, too. The next question to answer is the extent of the change. If only a partial change is required, i.e. the process is mostly functional, the plan only needs to 'tune' the problematic parts. The improvement plan will only take the form of corrective measures on the current processes. If the process is mostly dysfunctional, a 'clean slate' change, i.e. redesigning the whole process, is required.

\section{Table 3 - Collection of initial information}

\begin{tabular}{l|l|l|l}
$\mathbf{N r}$ & Question & TQM Element & BPR Element \\
\hline $\mathbf{1}$ & $\begin{array}{l}\text { What will be the subject of } \\
\text { improvement? }\end{array}$ & $\begin{array}{l}\text { Individual process, } \\
\text { system element }\end{array}$ & $\begin{array}{l}\text { The main process, macro } \\
\text { process }\end{array}$ \\
\hline $\mathbf{2}$ & $\begin{array}{l}\text { Who will benefit from the } \\
\text { change? }\end{array}$ & $\begin{array}{l}\text { Internal and external } \\
\text { customers, employees }\end{array}$ & Only external customer \\
\hline $\mathbf{3}$ & $\begin{array}{l}\text { What range of change is } \\
\text { needed? }\end{array}$ & Incremental change & Radical change \\
\hline $\mathbf{4}$ & How much time do we have? & Longer time & Short time (time pressure) \\
\hline $\mathbf{5}$ & $\begin{array}{l}\text { What direction is better to } \\
\text { make a change? }\end{array}$ & Bottom-Up & Top-Down \\
\hline $\mathbf{6}$ & $\begin{array}{l}\text { Who will implement the } \\
\text { change? }\end{array}$ & Involvement of all & Implementation teams \\
\hline $\mathbf{7}$ & $\begin{array}{l}\text { What frequency of } \\
\text { improvement is needed? }\end{array}$ & Continuous improvement & A single change
\end{tabular}

The fourth question to answer is 'How much time do we have?' With a longer time interval at hand, the particular steps of the implementation can have a looser schedule and they will not require intensive involment from the employees. With a lack of time, a tight schedule has to be applied. This will require a great dedication from the employees subject to the change, i.e. they might only have to dedicate their time to the changes implementation and the management will have to accept the fact. Furthermore, it is necessary to define which way to realize the change - upwards or downwards, which will then determine the way the employees will be trained. Question number six is aimed on who will realize the change. If the change means involving all the employees (everyone must be involved in the implementation plan), an overall motivation for the change needs to be carried out. If the change happens via implementation teams, only the team members need to be motivated. The last question surveys the need of repeating the improvement activities. If the need is to get better and better results in the area, i.e. a continuous change of the measures of efficiency, applying and 
implementing a simple change plan will not be sufficient. A 'cumulative improvement plan' will be required, i.e. after the completion of one plan of improvement, other solutions will have to be found to improve the process again (and the specific measures of efficiency). If it is only needed to remove a certain part of a non-functioning process and there is no need to get better and better results in the area (process), a one-time plan will be sufficient.

Point 2: Preparing the implementation plan

This is the time to bring the implementation plan to life. The pland needs to include the information acquired in Step 1, the structure of the plan needs to contain things like the definition of the corrective measures to be taken, the steps of the implementation of the measures, the planned closing time, the real closing time of the process, the person responsible, the costs of the implementation, the status of the corrective actions. Such a plan does not only provide an overview of the particular steps, the status of measures, the people responsible, but also of the costs the organization will have to invest in corrective action. This tool captures the tasks and steps essential to achieving a successful implementation. (Ballis, 1996:133)

\section{- Step 4: Implementation}

In this step, the activities from the implementation plan from step 3 will be performed. It is necessary that the design team supervise the realization of the individual steps and also keeping the deadlines.

\section{Phase 4 - Control}

In this phase, the achieved results will be compared with the initial status of the key performance indicators. It is good if the size of improvement is also calculated in percentage values. Based on the comparison, we can determine the progress that we have achieved by the implementation of corrective measures. In case it is possible, it is appropriate to calculate the total savings for a given time period (normally one year) and compare them with the costs for the implementation of the corrective actions. We can quantify the overall benefit of the project this way.

\section{Phase 5 - Continuous Improvement}

Finally, there is a necessity for each organization to continuously improve their processes. It is to find future opportunities for improvement. This means that after one improvement project another project should be started, using this 5phase methodology for process improvement.

\section{RESEARCH CONTRIBUTION}

There are several studies by various experts, showing that it is possible to integrate and use TQM and BPR jointly within one organization at the same 
time. But none of the research studied showed the way how to use the strengths of both methodologies simultaneously. In this paper, the writers have tried to integrate the elements of both TQM and BPR in a complex methodology and it showed that the integration of these approaches to process improvement is possible. In the future research, the proposed methodology will be implemented in real a situation of a production organization.

\section{CONCLUSION}

TQM and BPR are used by organizations with a different focus and after their implementation, achieving different results. Some organizations prefer TQM, others BPR. They are generally considered as two completely different approaches of process improvement that can not be integrated. Because of their common features, we can conclude that the integration is possible. Both approaches bring significant results in organizations that implement them. If organizations use the strengths of both methodologies for process improvement jointly, they could achieve more significant results as if they were used separately. The aim of this paper was to provide a manual how it is possible to integrate the elements of TQM and BPR into a one complex methodology.

\section{REFERENCES}

Allender, H. D., 1994. "Is reengineering compatible with Total Quality Management?", Industrial Engineering 26 (9), pp. 41 - 44.

Ballis, J. P, 1996. TQM-III: An alternative to reengineering, Flow Management \& Associates, Inc., Dallas, USA.

Carpinetti, L. C. R., Buosi, T. and GeroÂlamo, M. C., 2003. "Quality management and improvement. A framework and a business-process reference model", Business Process Management Journal, Vol. 9 No. 4, pp. 543 - 554, [pdf] Available at: <http://www.prod.eesc.usp.br/gqm/images/stories/arquivos/ paper_business_process_management_journal.pdf> Accessed 18 July, 2013.

Dai, J., 2007. "Implement BPR and CPI to optimize the process of getting medicine in pharmacy: a comparison between Sweden and China", Reports from MSI 07117, pp. $1-70$, [pdf] Available at: <http://www.divaportal.org/smash/get/diva2:205444/FULLTEXT01.pdf> Accessed 25 September, 2013.

De Bruyn, B. and Gelders, L., 1997. "Process Re-engineering: a Review of Enablers", International Journal of Production Economics, Vol. 50 Iss. 2-3, pp. $183-197$. 
Lorente, M. et al., 1999. "TQM and business innovation", European Journal of Innovation Management, Vol. 2 Iss: 1, pp. 12 - 19, [pdf] Available at: <http://repositorio.bib.upct.es:8080/jspui/bitstream/10317/442/1/tqm3.pdf> Accessed 25 September, 2013.

Gonzalez, B. J., Martinez, L. A. R. and Dale, B. G., 1999. "Business process reengineering to total quality management: An examination of the issues", Business Process Management Journal, Vol. 5 Iss: 4, pp. 1 - 22, [pdf] Available at: $<$ http://repositorio.bib.upct.es/dspace/bitstream/10317/428/1/bpr.pdf > Accessed 18 July, 2013.

Gore, E. W., 1999. "Organizational culture, TQM, and business process reengineering: An empirical comparison", Team Performance Management, Vol. 5 Iss: 5, pp. $164-170$, [online] Available at: $<$ http://www.deepdyve.com/lp/emerald-publishing/organizational-culture-tqmand-business-process-reengineering-an-tgNuKyidWw>Accessed 18 July, 2013.

Grover, V. and Malhotra, M. K., 1997. "Business Process Re-engineering: a Tutorial on the Concept, Evolution, Method, Technology and Application", Journal of Operations Management, Vol. 15 No. 3, pp. 193 - 213.

Hammer, M. and Champy, J., 2004. Reengineering the Corporation: A Manifesto for business Revolution, New York: McGraw-Hill.

Harrington, J. M, 1995. Total Improvement Management: the New Generation in Performance Improvement, New York: McGraw-Hill.

Harvey, S. and Millet, B., 1999. "OD, TQM BPR: A comparative approach", Australian Journal of Management \& Organisational Behaviour, Vol. 2 No. 3, pp. 30 - 42, [pdf] Available at: <http://usq.edu.au/extrafiles/business/journals/ HRMJournal/ AJMOBarticles/OD-TQM-BPR.pdf> Accessed 18 July, 2013.

Hekelová, E., 2000. Firm culture - An integrating element of QMS and EMS, [online] Available at: <http://home.mit.bme.hu/ kollar/IMEKO-procfiles-forweb/congresses/WC-16th-Wien-2000/Papers/Topic\%2025/Hekelova.PDF> Accessed 29 November, 2013.

Imeri, S. and Kekäle, T., 2013. "Towards an understanding of the impact of TQM in firms in south east europe - a qualitative approach", Business Excellence and Management, Vol. 3 No. 3, pp. 1 - 17, [pdf] Available at: <http://beman.ase.ro/no33/1.pdf> Accessed 29 November, 2013.

Ishikawa, K, 1990. Introduction to Quality Control, 3A Corporation, Tokyo.

Kelada, J. N., 1994. "Is Re-engineering Replacing Total Quality", Quality Progress, Vol. 27 No. 12, pp. 79 - 83.

Lolidis , M., 2006. "Kaizen Definition \& Principles in Brief: A Concept \& Tool for Employees Involvement", Thessaloniki, pp. 1-42, [pdf] Available at: $\langle$ http://www.michailolidis.gr/pdf/KAIZEN08.pdf> Accessed 25 September, 2013. 
Love, P. E. D. and Gunasekaran, A., 1997. "Process Re-engineering: a Review of Enablers", International Journal of Production Economics, Vol. 50, pp. 183 197.

MacDonald J. and Dale B. G., 1999. "Business Process Re-engineering”, in Dale B. G. (Ed.), Managing Quality, 3rd Edition, Blackwell Publishers, Chapter 22.

Martonová, I., Šurinová, Y. and Paulová, I., 2013. "Analysis of TQM and BPR integrability in conditions of Slovak organizations", European International Journal of Science and Technology, Vol. 2 No. 6, pp. 159-170, [pdf] Available at:〈http://www.cekinfo.org.uk/images/frontImages/gallery/Vol_2_No._6/18.pdf> Accessed 29 November, 2013.

Omnex, 2013. Business Process Re-engineering, [online] Available at: <http://www.omnex.com/members/standards/bpr/business_process_reengineerin g.aspx> Accessed 18 July, 2013.

Paulova, I. "Chosen Methods of System Approach in Quality Management and TQM Effectivity Evaluation", Hochschule Anhalt (FH), Kothem

Pürstinger, G., 2005. "The European Innovation - Challenge", Quality Innovation Prosperity, IX/1 - 2005, pp. 71 - 87, [pdf] Available at: <http://qipjournal.eu/files/2005/KIP-1-2005.pdf> Accessed 18 July, 2013.

Salegna, G. and Farzaneh, F., 1996. "An integrative approach for selecting a TQM/BPR implementation plan", International Journal of Quality Science, Vol. 1 No. 3, pp. 6 - 23, [online] Available at: http://www.deepdyve.com/lp/emeraldpublishing/an-integrative-approach-for-selecting-a-tqm-bpr-implementationplan-7wE2AJ0L53, Accessed 18 July, 2013.

Susnienè, D. and Vanagas, P., 2005. "Integration of Total Quality Management into Stakeholder Management Policy and Harmonization of their Interests", Engineering Economics No. 4 (44) - 2005, pp. 71 - 77, [online] Available at: <http://internet.ktu.lt/lt/mokslas/zurnalai/inzeko/44/1392-2758-2005-4-4471.pdf> Accessed 24 September, 2013.

Šurinová, Y. and Paulová, I., 2009. "Globalization effects on customer specific requirements in automotive production", Research papers Faculty of Materials Science and Technology Slovak University of Technology in Trnava, Vol. 18 No. 28, pp. 101 - 106, [online] Available at:

<http://www.degruyter.com/view/j/rput.2010.18.issue-28/v10186-010-00133/v10186-010-0013-3.xml> Accessed 18 July, 2013.

Zgodavová, K. and Slimák, I, 1998. "Total Quality Management or Reengineering or Constraints Management for Universities", Quality Innovation Prosperity, II/2 - 1998, pp. 65 - 69.

Zgodavová, K. and Slimák, I., 2011. "Focus on success", Quality Innovation Prosperity, XV/1 - 2011, pp. 1 - 4, [online] Available at: <http://www.qipjournal.eu/index.php/QIP/article/view/36> Accessed 18 July, 2013. 


\title{
ACKNOWLEDGEMENT
}

This way I would like to thank to my PhD. tutor Assoc. Prof. Iveta Paulova, PhD. for help and valuable advices in writing this paper.

\begin{abstract}
ABOUT THE AUTHOR
Ing. Ivana Martonová, external $\mathrm{PhD}$. student, Slovak University of Technology in Bratislava, Faculty of Materials Science and Technology in Trnava, Institute of Industrial Engineering, Management and Quality, Paulínska 16, 91724 Trnava, Slovak Republic; Quality Engineer, Vacuumschmelze, s.r.o., Horná Streda 1325/14, 916 24, Slovakia, e-mail: ivana.martonova@stuba.sk; ivana.martonova@vacuumschmelze.com.
\end{abstract}

